\title{
Shaping the future of restorative dentistry service delivery in the UK
}

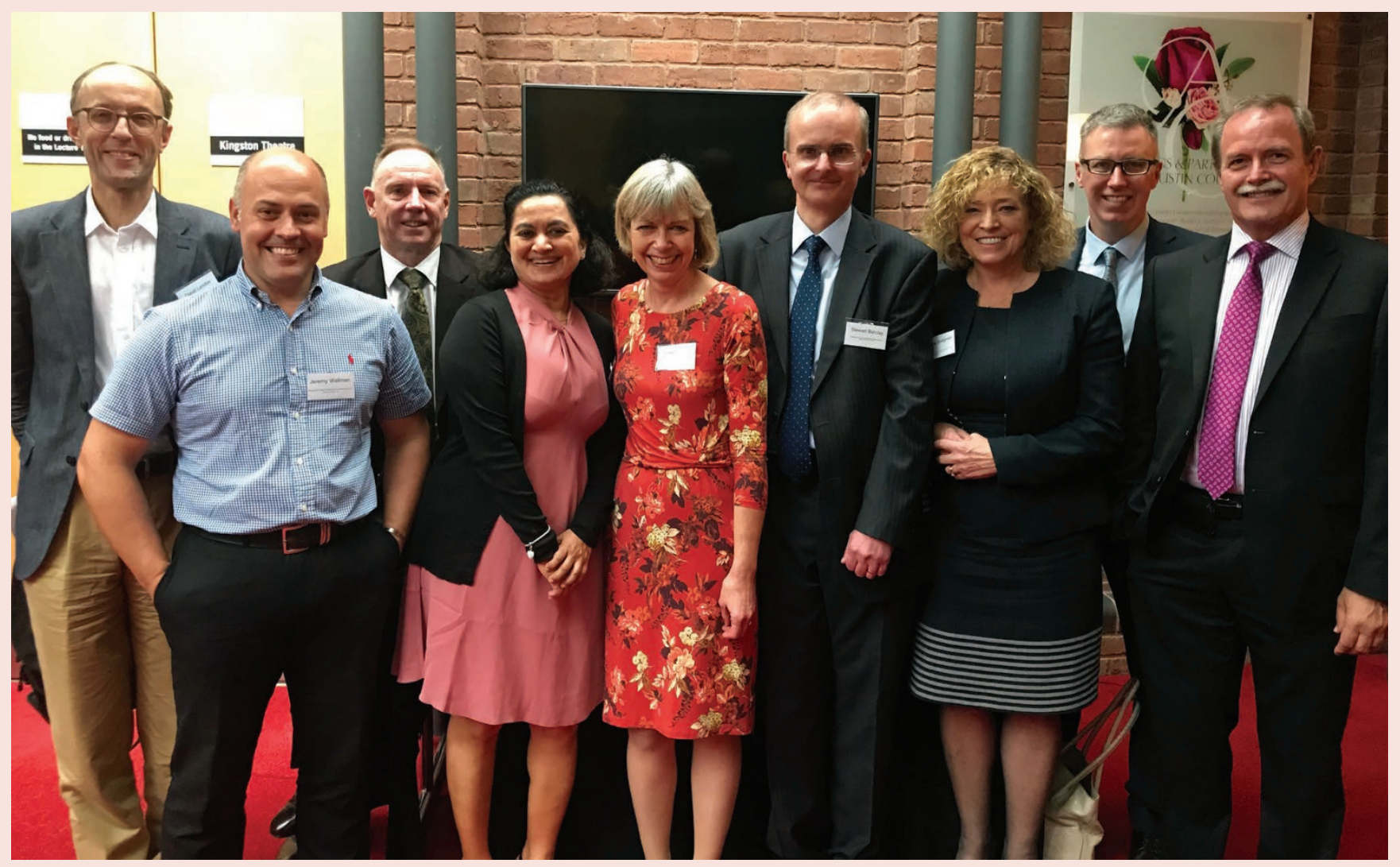

Speakers at the RD-UK annual conference in October 2017

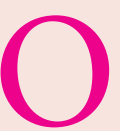

n 19 October 2017, Restorative Dentistry-UK (RD-UK) held its annual conference entitled

'Shaping the future of restorative dentistry service delivery in the UK' in Birmingham. The innovative meeting brought together under one roof key players in policy making and service provision and included CDOs, commissioners, consultants, trainees and chairs of local dental committees from across the country. It provided an opportunity for all involved in the decision-making for and delivery of specialist restorative dental services to discuss innovative ways to continue delivery of high quality clinical care in the NHS against a backdrop of financial constraints and new commissioning arrangements.

Held at the IET Austin Court, the day was coordinated and chaired by $\mathrm{Mr}$ Stewart Barclay, Honorary Secretary,
RD-UK. The morning session began with Miss Ulpee Darbar, Consultant in Restorative Dentistry and Chair of RD-UK, who, in describing what 'restorative dentistry' is and does, suggested that 'oral rehabilitation' may be a more appropriate term for the service given the increasing need for multidisciplinary and integrated, multi-faceted care within and outwith the speciality. Miss Darbar highlighted the profound impact on quality of life for patients that quality oral rehabilitation provides and that it was essential to achieving high quality patient centred care to have an integrated approach between GDPs, consultants and specialists, utilising managed clinical networks and facilitated by commissioners and policy makers.

Following this, Dr Janet Clarke MBE, the Deputy Chief Dental Officer, gave an overview of the upcoming changes in the primary care contract based on a blended model of mixed capitation and UDAs and the current work going into validating and accrediting Tier 2 complexity treatment. Dr Clarke also spoke about the introduction of 'Service Standards' which will supersede the current Commissioning Guides in order to ensure a minimum standard for commissioners.

This talk was followed by Mr Jeremy Wallman, Acting Head of Primary Care Commissioning for NHS England (London), who discussed the importance of a Consultant-led triage and electronic referral management system for specialist (including Tier 2) services and the value of patient and practitioner advice sheets to ensure appropriate quality of specialist referrals and communication with patients.

After a short break, Mr David Cheshire, Consultant in Restorative Dentistry, provided his personal experience of widespread current issues in dentistry 
4 where patient needs are not being met due to difficulty accessing secondary care and problems in delivery of routine primary care. He indicated clearly that this was due to multiple factors including high and on some occasions unrealistic patient expectations, an ever-ageing population, an unrealistic UDA remuneration system, growing litigation levels and a lack of clinical experience of new graduates. He reiterated the need to transform services to develop integrated clinical networks linking primary and secondary care sectors. This talk was followed by all delegates contributing to lively group discussions on local and national hurdles to service delivery experienced within their daily working lives.

The afternoon session resumed with Mr David Landes, Consultant in Dental Public Health, who addressed the need for Managed Clinical Networks (MCNs) in order to manage patient care pathways and the importance of shared care services with other disciplines such as special care dentistry. This was followed by four regional talks from colleagues from Wales, Ireland, England and Scotland outlining how services run (and differ) in each area. Ms Colette Bridgman, CDO for Wales, emphasised the importance of identifying individual and population needs and planning restorative services to meet those needs. She underlined the need to clarify information on outcomes of care by collecting data on patient related outcome/experience measures and quality of life in order to recognise the importance to these of quality restorative dentistry. $\mathrm{Mr}$ Michael Donaldson, Consultant in Dental Public Health from Ireland, explained service delivery and the primary care contract in Ireland - based on a fee per item service model - and summarised the growing demands of dentistry in Ireland.

Professor Nick Grey spoke about his experience of the MCN that was set up in Manchester along with the usefulness of an electronic referral system for triaging and obtaining information on referrers. Mr Martin Donachie from Scotland rounded off the regional views by giving a comprehensive account of a pilot endodontic 'MCN' programme currently running in Scotland, using funding re-directed from other un-used services. After the break, the afternoon ended with further group discussions on how to establish an MCN going forward and what the priorities should be for the future.

The overall message from the conference was of putting patients at the core of transformational change, generating ideas and working together. The conference gave a strong message of real hope and a true belief that restorative dentistry as a specialty is fundamental to dental services in the UK and that obstacles such as financial constraints, resource limitations and growing waiting times should be seen as opportunities for change, service development and improvement by allowing clinicians, commissioners and policy makers to work with and for patients to set standards and drive forward change for the future of the profession.

By Stewart C. Barclay on behalf of RD-UK 